\title{
Treatment Strategies in the Management of Proactive Skin Health and Anti-Aging Improvement- A Review
}

\section{Tejasswini $\mathbf{R}^{*}$}

Department of Pharmaceutics, JSS College of Pharmacy, JSS Academy of Higher Education and Research, India

*Corresponding author: Tejasswini R, M Pharmacy in Cosmeceutics, Department of Pharmaceutics, JSS College of Pharmacy, JSS Academy of Higher Education and Research, 35/1, MURUGAPPA LAYOUT, Mahalingapuram, Pollachi, India, Tel: 09566479362; Email: teanutejaswini@gmail.com

\section{Review article}

Volume 5 Issue 3

Received Date: July 05, 2020

Published Date: July 31, 2020

DOI: $10.23880 /$ cdoaj-16000215

\section{Abstract}

The term "aging" describes the totality of exposures of any individual experiencing the skin aging. It includes both external and internal factors as well as the human body's response to these factors. Current anti-aging treatment strategies aims to reverse the dermal and epidermal signs of photo- and chronological aging, yet today, the aging of human skin has received major attention and a corresponding treatments are highly concerned. This review was compiled with the collaboration of different research fields such as dermatological practices, cosmetic procedures, preventive measurements, topical medical agents, general therapeutic agents, invasive procedures, specialized in environmental medicine and other exogenous factors, skin biology and nutraceuticals. A comprehensive review of this literature was performed using PubMed. The search was restricted to current treatment strategies on skin aging. It is based on a summary of the existing non-invasive and invasive treatment strategies in skin aging. This review also helps to identify future treatment needs which concern knowledge about the interaction of these existing treatment strategies with each other and the resulting net effects on skin aging and suggest some protective measures.

Keywords: Ultraviolet Radiation; Visible Light; Infrared Radiation; Air Pollution; Nutrition Cosmetic Strategies; Anti-Aging; Hormone Replacement Therapy; Cell Regulators; Antioxidants; Photo Protection; Dermabrasion; Botulinum Toxin; Invasive Approach; Nutraceuticals; Cosmetic Procedures; Dermal Fillers; Preventive Actions; Marine Cosmeceuticals

Abbreviations: IRR: Infrared Radiation; ROS: Reactive Oxygen Species; UV: Ultraviolet Radiation; UVA; UVB; VL: Visible Light; mrf: Monopolar Radiofrequency; AHA: Alpha Hydroxy Acid; BHA: Beta Hydroxy Acid; FR: Free Radicals; TCA: Trichloroacetic Acid; GH: Growth Hormone; HRT: Hormone Replacement Therapy AGE; IPL: Intense Pulsed Light; RF: Radiofrequency; HA: Hydroxy Acid.

\section{Introduction}

\section{Ageless is Beauty}

Evolution of the cosmeceuticals science has been much advanced in these days. Standards of beauty have changed through centuries with increased awareness about Aesthetics. The face remains the main source of information for identification and discrimination. The human skin is the superior and largest of all organs in the human body which shows random significant changes as it is exposed to different conditions daily. Signs of ageing become evident as life progresses, and skin changes represent the primary proof of the ageing process. Most changes in ageing skin result from a combination of endogenous (e.g., gene mutations, cellular metabolism, hormones, environment) and exogenous (e.g., chemicals, toxins, pollutants, UV, and ionizing radiation) 
factors.

Exogenous or extrinsic ageing affects mostly sun-exposed body areas, while characteristic changes of endogenously or intrinsically aged skin are mainly visible in sun-protected skin areas. The latter can be considered representative of the ageing process taking place in internal organs. Through the degradation of skin cells, free radicals and inflammation weaken repair mechanisms and result in collagen and elastic fibre breakdown. With the accelerated influences of internal and external factors, skin ageing is highlighted by skin roughness, fine lines, skin wrinkling, pigmentation change, telangiectasias, loss of elasticity, and decreased firmness. By enhancing the proper diet and lifestyle changes, the ageing can be delayed along with the intake of suitable nutraceuticals which delays and fight against these internal and external factors, many of which are found in foods and by-products consumed naturally [1].

Some of the common and well-known anti-ageing strategies involve changing your diet, exercising, staying hydrated, and using over-the-counter skincare products that will help to reduce the appearance of fine lines and wrinkles while preventing new ones from forming [2].

Other skin anti-ageing treatments involve visiting a professional derma-clinic for fillers and surgical procedures that could lift the aged skin and tighten your skin to give a more youthful appearance. Some of the best anti-ageing treatments are consulting a dermatologist and getting a prescription of suitable anti-wrinkle cream that would deliver considerable results. But if you want the fastest results, undergoing a cosmetic procedure or treatment that will tighten your skin and fill in your wrinkles is the way to go [3]. The most important source of antioxidants is provided by diet and nutrition. The most known systemic antioxidants are vitamin $\mathrm{C}$, vitamin $\mathrm{E}$, carotenoids, and from the trace elements copper and selenium. The possible way to delay skin ageing and to improve skin conditions through the administration of selected nutritional supplements.

Nutritional antioxidants have different mechanisms but are mainly FR scavengers:

1. Directly neutralize FRs.

2. Reduce the peroxide concentrations and repair oxidized membranes.

3. Quench iron to decrease ROS production.

4. via lipid metabolism, short-chain free fatty acids and cholesteryl esters neutralize ROS [3].

There are also studies demonstrating that vitamins $\mathrm{C}$ and $\mathrm{E}$ combined with ferulic acid impart both a sunscreen and an antioxidant effect.
This review aims to detail the aesthetic antiaging strategies from Anti-wrinkle cream to latest filter treatments and also this review will be an aid for dermatologists in understanding the mechanism of action of various antiaging products and treatment strategies along with nutraceuticals and their potential effectuality in antiaging and skin health. Hence, the emerging demand for cosmetic treatments to reduce facial wrinkles, fine lines and laxity have motivated me to search for various published articles on both surgical interventions and nonsurgical treatment procedures for the enhancement of facial beauty. The review analysed the published data to provide a narrative basic review in a concise way to the beginners, clinicians, and students.

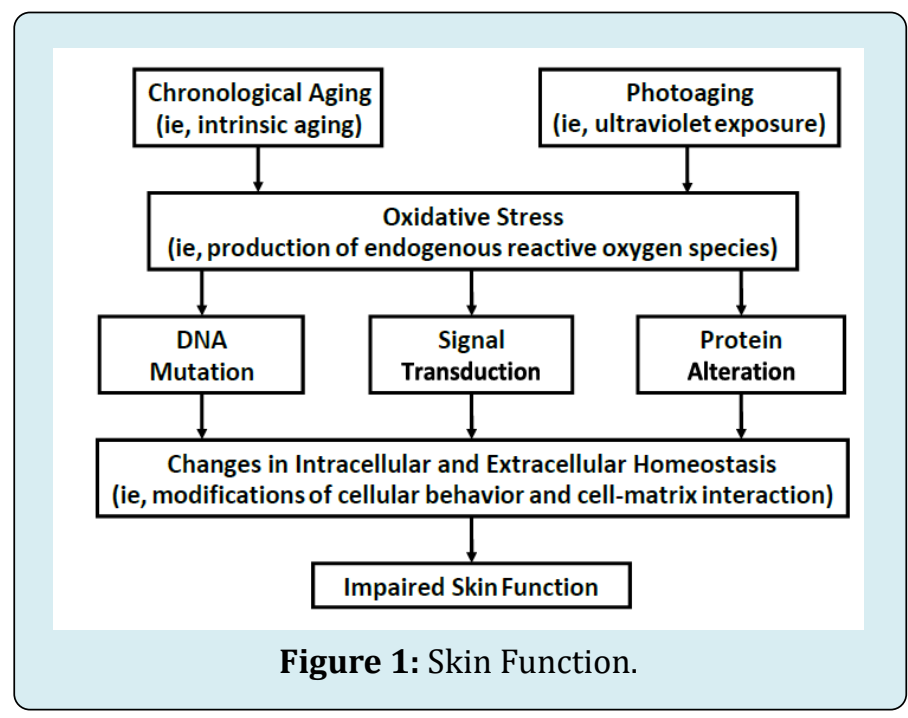

\section{Methodology}

This paper follows the defined and analysed the key elements of skin aging factors, in view of the existing literatures. The author has performed a comprehensive literature search using PubMed, science direct and google scholar, with combinations of the following keywords: skin aging; skin damage; skin pigmentation and sun exposure; hormone replacement therapy; cell regulators; antioxidants; photo protection; dermabrasion; botulinum toxin; invasive approach; nutraceuticals; cosmetic procedures; dermal fillers; preventive actions; sunlight; UV radiation; UVB radiation; UVA radiation; visible light; infrared radiation; air pollution; tobacco; stress; physical activity; diet; nutrition; alcohol; antioxidants; cosmetics; skincare; makeup; cosmetic procedures; heat; cold; climate; water; lack of sleep. All relevant review papers including the non-invasive procedures and clinical studies were selected.

\section{Skin Aging Prevention and Treatment Strategies}

The treatment strategies are basically a set of procedures followed for longevity of the skin [4]. 


\section{Clinical Dermatology Open Access Journal}

\begin{tabular}{|c|c|c|c|c|}
\hline \multirow{2}{*}{ Treatment } & \multirow{2}{*}{$\begin{array}{c}\text { Onset } \\
\text { improvement }\end{array}$} & Discomfort/ & \multirow{2}{*}{ Effect duration } & \multirow{2}{*}{$\begin{array}{c}\text { Expected } \\
\text { Improvement }\end{array}$} \\
\hline & & Recovery & & \\
\hline Topical treatments & \multirow{6}{*}{2 - 3 months } & \multirow{6}{*}{ None } & \multirow{6}{*}{$\begin{array}{c}\text { All topical treatments requires } \\
\text { continuous use }\end{array}$} & \multirow{6}{*}{ None - subtle } \\
\hline Retinoids & & & & \\
\hline Hydroxy acids & & & & \\
\hline Kinetin & & & & \\
\hline Antioxidants & & & & \\
\hline Copper peptides & & & & \\
\hline Microdermarasion & $0-1$ day & $0-1$ day & Requires repeat treatment & None - subtle \\
\hline \multicolumn{5}{|l|}{ Chemical peels } \\
\hline Superficial & $2-3$ peels & 0 - 4 days & 2- 4 months & None - subtle \\
\hline Medium & 2- 4 weeks & 7- 12 days & 1- 2 years & Subtle - moderate \\
\hline Deep & 4- 8 weeks & 2- 4 weeks & $2-5$ years & Moderate - severe \\
\hline Botulinum toxin & $1-3$ days & $0-3$ days & $3-6$ months & None - Severe \\
\hline Dermal fillers & Immediate & $0-1$ week & Variable & None - Severe \\
\hline \multicolumn{5}{|l|}{ Laser / light sources } \\
\hline $\begin{array}{l}\text { 1. Pigment / Telangiectasia } \\
\text { removal }\end{array}$ & $1-6$ weeks & $1-3$ weeks & $1-5$ years & None - Severe \\
\hline 2. Ablative skin resurfacing & $1-4$ weeks & 1- 4 weeks & $3-7$ years & Moderate - Severe \\
\hline $\begin{array}{l}\text { 3. Non ablative skin } \\
\text { resurfacing }\end{array}$ & $2-9$ months & 1 - 4 hours & Variable & None - Severe \\
\hline Dermabrasion & $1-4$ weeks & $1-4$ weeks & $3-7$ years & Subtle - moderate \\
\hline Radio frequency devices & $1-3$ weeks & 1-24 hours & Unknown & None - Severe \\
\hline Cosmetic surgeries & 1- 6 weeks & 1-6 weeks & $5-7$ years & Subtle-moderate \\
\hline
\end{tabular}

Table 1: Treatments strategies for Skin Aging

\section{Cosmetological Self-Care}

Everyday skincare routine with correct sun protection will influence the maintenance of healthy young skin. Daily skincare may increase skin regeneration, elasticity, smoothness, and thus temporarily change the skin condition. Everyday skincare will protect the skin against any allergens, pollutants, Reactive oxygen species, and dehydration against radiation exposure. Good skincare routine and healthy lifestyle choices can help delay natural aging and prevent various skin problems, the process of daily skincare includes sun protection and gentle cleansing which can keep the skin healthy and glowing. The double cleansing method is recommended greatly for the complete skin cleansing without any makeup or other product residues on the skin. The use of skin cleansers which enhances the barriers of the skin and moisturizers can both maintain and aid in the restoration of skin health. New developments, particularly in the realm of oil-based, water-based cleansers and Niacinamidecontaining moisturizers, offer therapeutic solutions for photo-damaged and healthy skin [5]. Exfoliation in skin cleansing routine will remove any photo-damaged cells from the skin surface which can be done by using physical, enzyme or acid exfoliants like AHA salicylic acid or lactic acid [6].

\section{Sunscreens}

The sunblock creams or lotions will protect the skin daily by reducing the photo-induced skin damage. Many telltale signs of aging, such as the formation of wrinkles, the appearance of pigmentations, dilation of blood vessels, and loss of collagen, are accelerated by UV exposure. Routine use of sunscreen can attenuate and slow down this process. In the treatment of photodermatoses, the sunscreens are used in first line therapy of the treatment $[7,8]$. Any physician will begin to stress the importance of sunscreen having the beneficial effects of any other skin rejuvenation steps in the antiaging treatment.

\section{Hormone Therapy}

Hormonal Replacement Therapy (HRT) means 
maintaining youthful skin has been a topic of great interest. Oral HRT improves skin moisture, elasticity and thickness, but showed some unacceptable adverse effects on women. It is well known that there is is a progressive decrease in hormone synthesis with age [9]. Levels of growth hormone (GH) and insulin-like growth factor-1 (IGF1), melatonin (nocturnal), TSH, thyroid hormones (T3), dehydroepiandrosterone (DHEA) (sulphated form and its urinary 17-keto-metabolites), oestrogens and testosterone are progressively decreasing. The main hormonal deficits in humans are menopause, andropause and partial androgen deficiency of the aging male $[10,11]$. Melatonin influences the aging process because it has an inverse effect concerning body weight; food restriction raises the levels of melatonin and decreases its age-related decrease. With increasing age comes a decrease in melatonin production, there will be some sleeping disorders suffered by elderly people. Estriol, a well-known anti-ageing medicine as an HRT. Growth Hormone $(\mathrm{GH})$ is widely used in antiaging medicine to reverse the effects of aging [12]. GH supplementation as an antiaging medicine for healthy elderly individuals with low $\mathrm{GH}$ levels due to age is still a matter of debate, with unclear details. Antiaging specialists promote the use of bioidentical hormones as a more natural way to supplement hormone deficiencies in postmenopausal women [13]. Theoretically, it is very easy to be able to supplement with an identical hormone compound to the one lacking. But, the natural hormones which participate in most of the body's functions at different degrees, and hormone analogues may only partially fulfil the multiple roles of the natural hormone [14].

\section{Topical Cosmeceuticals}

Cosmeceuticals are the class of products that merge cosmetics and pharmaceuticals meaning they contain topical attributes of cosmetics but include ingredients that influence biological functions of the skin. To counteract the biological occurrences taking place on the cellular level to lessen the perceivable effects of aging and to formulate them into the commercial products [15]. The two categories of cosmeceutical active agents used for anti- aging cream formulations are the antioxidants and the cell regulators.

\section{Topical Antioxidants and the Cell Regulators}

Vitamins - A, C \& E, Polyphenols - Grape seed extract, green tea \& resveratrol, Flavonoids. They reduce collagen degradation by reducing the concentration of FR in the tissues. ROS activates the MAPK pathway and subsequently increase MMP production that degrades collagen. This can be prevented by antioxidants such as vitamin $\mathrm{C}$ and vitamin E, or anti-oxidative enzymes, such as superoxide dismutase, catalase, glutathione peroxidase, and coenzyme Q10. Antioxidant treatment aims to restore oxygen homeostasis instead of eliminating all oxidants because they have their physiological functions. Thus, for the necessary clinical application of antioxidants, the doctor should evaluate the status of the patient before giving a prescription. It's not desirable to completely inactivate all ROS, and antioxidant treatment seems to be beneficial for aging (including skin aging) only if the ROS level is reduced to those of healthy cells [16-20]. The cell regulators, such as Retinols, AHA \& BHA, Peptides, Growth factors (GF). These have direct effects on collagen metabolism and influence collagen production.

\section{Topical Retinoids}

Topical cosmeceuticals like vitamin A and its derivatives such as retinoids ( $R_{x}$ Topicals in few countries) which are intended in order to inhibit collagenase synthesis and to promote collagen production, and anti-oxidants, particularly in combination, to reduce and neutralize free radicals (FR) [16]. Retinoids are chemically similar to vitamin A, and tretinoin is the first retinoid approved for clinical use. Topical application of tretinoin inhibits AP-1, thus suppressing the expression of MMPs and preventing the degradation of collagen. An increase in epidermal thickness and anchoring fibrils is observed, and intrinsically aged skin may also benefit from the topical application of retinoids [21]. The two primary functions of retinoids in the body are the antioxidant activity on scavenging peroxyl radicals, quenching singlet oxygen, and their ability to affect specific genes to activate growth factors and keratin production. Retinol aids in increased cell renewal leading to a decrease in the appearance of fine lines and wrinkles, toning the skin and brightening its complexion [22,23].

\section{Alpha and Beta Hydroxy Acids}

Alpha hydroxy acid (AHA) and Beta hydroxy acid (BHA) both are naturally occurring substances in fruits, wine, milk and sugarcane. Topical cosmeceutical products containing $20-30 \%$ of HA concentrations will help to even the skin pigmentation [15]. HA lotion with $25 \%$ of AHA concentration at $\mathrm{pH} 3.5$ treats severe photo damaged skin. HA increases the collagen gene expression and cell turn over when applied to the damaged skin [24,25]. Alpha hydroxy acids (AHAs) in conjunction with vitamins B3, C, and E has many advantages on the rejuvenation of the aged facial skin [24]. The benefits of AHAs in the antiaging skin system with Nicotinamide (Active form of vitamin B3) will improve the skin barrier function and appearance [25]. Vitamin C, to help repair agerelated damage and Vitamin E, for minimizing free-radicalinduced damage $[17,5,26]$.

\section{Other Topical Antioxidants}

Vitamins $\mathrm{C}$ and $\mathrm{E}$, selenium, genestein, and coenzyme Q10 not only protect from but also reverse photo-aging 
if the correct molecular forms and concentrations are applied [26]. Vitamin C stimulates the collagen synthesis therefore reducing the appearance of fine lines and wrinkles, improvement of skin tone for a healthy complexion and the neutralization free radicals to help protect against photoaging. Ascorbic acid has strong antioxidant activity and helps maintain vitamin $E$ in its active form in the body which is a strong antioxidant thus combination therapy of Vitamin C \& E were used [27].

\section{Polyphenols}

The green tea has epigallocatechin-3-gallate (EGCG) which is 15 to 2 times more powerful antioxidant than vitamin C \& E. Resveratrol has hydroxyl-radical scavenging activity, in particular, quenching the superoxide anion and inhibiting hydrogen peroxide production. It has been found to have glutathione-like activity protecting the cells from oxidative stress $[28,29]$.

\section{Marine Cosmeceuticals}

Marine algae's are abundant sources of bioactive compounds with cosmeceutical potential which has beneficial effects to the skin, including antioxidant, anti-melanogenic and skin anti-aging properties [30]. Marine resources have been recognised for their biologically active substances. Marine algae are rich-sources of metabolites, which can be used to fight against oxidative stress and skin aging. These metabolites include, among others, mycosporine-like amino acids (MAAs), polysaccharides, sulphated polysaccharides, glucosyl glycerol, pigments, and polyphenols [31]. Marine fungi's are providing several new secondary metabolites, these secondary metabolites isolated from marine fungi have a range of cosmeceutical application such as anti-ageing, skin-whitening and anti-acne [32].

\section{Stem Cell Therapy}

The most significant skin rejuvenation process is collagen remodelling and in that case stem cell transplantation is a promising therapy for the treatment of skin aging. Adipose tissue transplantation could improve skin quality at the recipient site in addition to increasing skin volume. Further experiments demonstrate that adipose-derived stem cells (ADSCs) contribute to the regeneration of skin during aging. In recent clinical tests, autologous fat grafting rejuvenates aging skin and enhances the volume of periocular and perioral skin in recipients with an average age of 50 years. Data show that ADSCs produce a series of growth factors, such as vascular endothelial growth factor (VEGF), basic fibroblast growth factor (bFGF), transforming growth factor (TGF)- $\beta 1$, TGF- $\beta 2$, hepatocyte growth factor (HGF), keratinocyte growth factor (KGF), platelet-derived growth factor AA (PDGF-AA), and placental growth factor (PGF), remind that ADSCs may influence surrounding cutaneous cells through these secretions. It seemed that ADSC may also transdifferentiate into epithelial stem cells that express epithelial stem cell marker p63 after fat grafting [1,33-35].

\section{Surgical Interventions / Procedures}

\section{Aesthetic Procedures - Non-invasive and Invasive Procedures}

The Non-invasive aesthetic procedures are minimal non-surgical treatments where injectables and chemical based treatments used reduce wrinkles and fine lines. Specifically designed instruments and skilled cosmetic surgeons are able to achieve minimal incision to the skin and provides minimally invasive treatments with today's advances. Today's non-invasive plastic surgery methods have met their match with minimal invasive surgical treatments, although the pain and scarring has reduced with invasive facial cosmetic surgery. Non-invasive cosmetic treatment has surpassed minimally invasive treatment. As facial cosmetic procedures are ideal for people who prefers a preventative, speedy procedure, and a more cost-effective treatment. Non-invasive cosmetic procedures have a number of different options in order to achieve the desired look of the patients. Although non-invasive cosmetic procedures do not have a permanent effect, they do last a long period of time [20]. In clinical practice the non-invasive anti-aging treatments are, micro-needling, microdermabrasion, dermal fillers, chemical peels. Invasive treatment procedures are more like the cosmetic surgeries performed only by the licenced an experienced aesthetic practioner. Some Invasive treatments are deep chemical peeling, visible light, Intense pulse light (IPL), Laser photo-rejuvenation, radio frequency (RF), Injectable Skin Biostimulation, correction of static and anatomical wrinkles, restoration of fat $\&$ volume loss, skin augmentation and contouring [36,37].

\section{Chemical Peels}

Chemical peels have a long history of use for skin rejuvenation. The peel applies a chemical which removes external layer of damaged skin in order to improve appearance of the skin. Which is replaced by a new rejuvenated layer of skin as it regenerates. These results vary on the severity of the type of chemical peel however, the results are temporary as the new layer of skin becomes damaged from exposure [38]. Whilst there is a plethora of new devices on the market for improving skin tone and texture, there has been a huge resurgence in adding chemical peels to clinical protocols [18]. The chemical peel can be divided into superficial, medium depth and deep layers as these distinctions are important as 
the magnitude of the effect is associated with several factors like risk and recovery time. The superficial peels (stratum corneum to papillary dermis $60 \mathrm{~m}$ ) will injure the epidermis and include salicylic acid (concentration 10-70\%), trichloroacetic acid (concentration 10-25\%) Jessner's solution (resorcinol 14g, salicylic acid 14g, 85\% lactic acid $14 \mathrm{~g}$, and $95 \%$ of ethanol quantity sufficient to add up to $100 \mathrm{cc}$ ). Multiple peels are performed at regular intervals such as weekly, bi-weekly, monthly to achieve the desired results. Statistically improvements are decreased rough skin texture, improvement of fine lines/ wrinkles, decrease in the number of solar keratosis. Medium depth chemical peels (a depth of approximately $0.6 \mathrm{~mm}$ ) Jessners solution + trichloroacetic acid or 35 - 50\% trichloroacetic acid alone are commonly used. $70 \%$ glycolic acid $+35 \%$ TCA effectively remove actinic keratosis. Deep chemical peels the peeling agent called The Baker/Gordon formula ( $3 \mathrm{ml}$, phenol, USP, $2 \mathrm{ml}$ of distilled water, 8 drops of liquid soap, 3 drops of croton oil) is used for the classic deep chemical peel. The peel causes injury to reticular epidermis, which increases the risk, but results in new collagen formation and reduce wrinkle formation. Treats conditions like severe photoageing (advanced rhytides), pigmentary disorders, premalignant skin tumours, scars [39].

A well-executed peel series will reveal a smooth, revitalised texture through regenerating new epidermal cells and resurfacing the skin. Salicylic acid, lactic acid, mandelic acid, fruit enzyme such as papain, retinoids and modified Jessners are now considered the ideal ingredient options for peels $[40,41]$.

\section{Combination Techniques}

Chemical peels are often combined with other cosmetic procedures for cutaneous resurfacing. This synergistic approach to facial rejuvenation provides a fast, cost effective and less invasive alternative to surgery.

\begin{tabular}{|c|c|c|}
\hline Combination Technique & Procedure / Method & Results / Outcome \\
\hline $\begin{array}{l}\text { Microdermabrasion }+ \\
\text { Chemical peels: }\end{array}$ & $\begin{array}{l}\text { This method involves the mechanical } \\
\text { exfoliation of skin by the application of } \\
\text { microcrystals. }\end{array}$ & $\begin{array}{l}\text { Effective in treatment of photo-ageing, } \\
\text { moderately deep rhytides and acne scars. }\end{array}$ \\
\hline $\begin{array}{c}\text { Microneedling + Chemical } \\
\text { peels: }\end{array}$ & $\begin{array}{l}\text { Percutaneous collagen induction therapy } \\
\text { which involves the penetration of the } \\
\text { stratum corneum into the papillary dermis } \\
\text { with needles }\end{array}$ & $\begin{array}{l}\text { This results in the formation of micro- } \\
\text { channels and a demarcation current that } \\
\text { stimulates the release of growth factors } \\
\text { that are involved in neo-collagenesis and } \\
\text { neo-angioenesis. Combined with glycolic } \\
\text { acid to manage acne scars. }\end{array}$ \\
\hline $\begin{array}{l}\text { Botulinum toxin- } A \\
\text { injections (BTX-A) + } \\
\quad \text { Chemical peel: }\end{array}$ & $\begin{array}{l}\text { Effective in facial rejuvenation. Excessive } \\
\text { toxin dispersion may cause marked } \\
\text { inflammation. }\end{array}$ & $\begin{array}{l}\text { Relaxation of facial muscles are required } \\
\text { for complete cure of inflammation. }\end{array}$ \\
\hline $\begin{array}{l}\text { Dermal fillers }+ \text { Chemical } \\
\text { peels: }\end{array}$ & $\begin{array}{l}\text { Soft tissue augmentation with hyaluronic } \\
\text { acid may also be combined with superficial } \\
\text { chemical peeling. }\end{array}$ & \\
\hline $\begin{array}{l}\text { Ablative laser resurfacing } \\
\quad+\text { Chemical peel: }\end{array}$ & $\begin{array}{l}\text { Individuals with mixed photo-ageing such as } \\
\text { combination complexion and volume issues } \\
\text { may benefit from the sequential application } \\
\text { of ablative laser and medium-depth chemical } \\
\text { peeling in one session to different areas }\end{array}$ & $\begin{array}{c}\text { For example, TCA } 35 \% \text { is applied to the } \\
\text { skin first, followed by fractionated carbon } \\
\text { dioxide laser to treat periorbital and perioral } \\
\text { rhytides. }\end{array}$ \\
\hline
\end{tabular}

Table 2: combination techniques with chemical peel

\section{Botox (Botulinum toxin)}

Because of non-invasive methods having vast popularity among patients seeking to achieve facial rejuvenation, physicians from diverse specialties have integrated botulinum toxin injections into their existing practices [42]. With this method, the targeted muscles which form unwanted wrinkles are weakened. Botox is a quick and effective wrinkle solution which generally lasts three to six months. Botulinum toxin products for cosmetic applications that have received regulatory approval or are under development.

\section{Dermal Fillers}

For immediate and effective results, dermal fillers(soft tissue fillers) are applied to rejuvenation of wrinkle and 
fine lines. Facial filler injections are taken depending on the targeted area and the product used. For example, Collagen fillers last a couple of months. Hyaluronic Acid Fillers may last six months to a year and hyaluronic acid fillers are showing more evidence of creating a permanent antiaging effect by promoting the collagen growth [43]. Synthetic fillers such as Radiesse, Calcium Hydroxylapatite Fillers last a little over a year and Poly-L-Lactic Acid Fillers two years before the body breaks it down and absorbs the solution $[44,45]$.

\section{Dermatological Lasers}

Rapid technical developments with different fractional lasers for drug delivery or combination treatment of cosmeceuticals are used for antiaging treatments. mRF devices have been shown to be clinically effective for treating aging skin [34]. 1550, 1927 and 2940 $\mathrm{nm}$ wave lengthen fractional lasers were treated on splited face for each subject one of the cosmeceuticals containing antiaging molecules L-ascorbic acid, retinol or tranexamic acid. Multi-spectral spectroscopy and Cutometer was used to check the parameter change for each session. The first phase with short-term followup showed a significant superiority in the group with $1927 \mathrm{~nm}$ and $2940 \mathrm{~nm}$ than $1550 \mathrm{~nm}$ treated. L-ascorbic acid showed improvement in elasticity and brightness. Retinol showed improvement in wrinkle depth and size. Tranexamic acid showed brightening effect [46,37].

\section{Exogenous Factors - Diet Restriction, Nutrition and Smoking Habits}

Avoiding exogenous factors of skin-aging by correction of lifestyle and habits such as smoking, stress, pollution, solar \& UV radiation, diet restrictions, nutrition and alimentary supplementation, physical activity and control of general health. The primary strategy is the prevention of proteins from glycation, but it's practically not possible to reverse glycated proteins to their original state $[47,48]$.

Therefore, some compounds such as garlic ginger, flavonoids in green tea (catechins), $\alpha$-tocopherol, Niacinamide, pyridoxal, sodium selenite, selenium yeast, riboflavin, zinc, and manganese involves in inhibition of AGE formation and some culinary herbs \& spices such as such as cinnamon, cloves or oregano also inhibits the fructose-induced glycation. More investigation is needed to further validate these findings and reveal their inhibitory mechanisms $[49,50]$.

\section{Concluding Remarks}

The aging is a naturally occurring process of any individual human body, including the dermal skin which shows visible remarks in the recognition of the external appearance. Cosmeceutical Aging and wrinkle treatment ingredients are becoming increasingly sophisticated and functional, and the current level of development of these components allows the production of products with actions and activities that could not have been predicted a short time ago.

The Prevention of the skin-aging can be achieved by the everyday cosmetological self-care, sunscreens for photoaging and use of topical cosmeceuticals which prevents and treats the underlying collagen. Surgical interventions such as chemical peels, microdermabrasion and dermatological lasers are scientifically proven and the treatments in trend for Skin-aging. Now a days, in the skincare market research, various therapeutic interventions and technical information on skincare products are easy to access. Thus there is a rapid increase on proven efficiency of antiaging therapies. This has led to the improvement of the Proactive skin health and improving effects on antiaging treatments.

\section{References}

1. Shetty K, Kodali M, Upadhya R, Madhu LN (2018) Emerging anti-aging strategies - Scientific basis and efficacy. Aging and Disease 9(6): 1165-1184.

2. Yadav T, Mishra S, Das S, Aggarwal S, Rani V (2015) Anticedants and natural prevention of environmental toxicants induced accelerated aging of skin. Environmental Toxicology and Pharmacology 39(1): 384-391.

3. Souyoul SA, Saussy KP, Lupo MP (2018) Nutraceuticals: A Review. Dermatology and Therapy 8: 5-16.

4. Grossman $\mathrm{T}$ (2005) Latest advances in antiaging medicine. Keio Journal of Medicine 54(2): 85-94.

5. Draelos ZD (2008) Clinical situations conducive to proactive skin health and anti-aging improvement. Journal of Investigative Dermatology Symposium Proceedings 13(1): 25-27.

6. Zouboulis C, Ganceviciene C, Liakou AI, Theodoridis A, Elewa R, et al. (2019) "Aesthetic aspects of skin aging, prevention, and local treatment. Clin Dermatol 37(4): 365-372.

7. Wang SQ, Balagula Y, Osterwalder U (2010) Photoprotection: A review of the current and future technologies. Dermatol Ther 23(1): 31-47.

8. Shanbhag S, Nayak A, Narayan R, Nayak UY (2019) Antiaging and sunscreens: Paradigm shift in cosmetics. Advanced Pharmaceutical Bulletin 9(3): 348-359. 


\section{Clinical Dermatology Open Access Journal}

9. Quatresooz P, Piérard-Franchimont C, Gaspard U, Piérard GE (2006) Skin climacteric aging and hormone replacement therapy. Journal of Cosmetic Dermatology 2(3): 283-297.

10. Raine-Fenning NJ, Brincat MP, Muscat-Baron Y (2003) Skin aging and menopause: Implications for treatment. American J Clinical Dermatology 4(6): 371-378.

11. Lephart ED (2018) A review of the role of estrogen in dermal aging and facial attractiveness in women. Journal of Cosmetic Dermatology 17(3): 282-288.

12. Son DH, Park W, Lee Y (2019) Recent Advances in AntiAging Medicine. Korean J Fam Med 40(5): 289-296.

13. Lephart ED (2016) Skin aging and oxidative stress: Equol's anti-aging effects via biochemical and molecular mechanisms. Ageing Research Reviews 31: 36-54.

14. Samaras N, Papadopoulou MA, Samaras D, Ongaro $F$ (2014) Off-label use of hormones as an antiaging strategy: A review. Clinical Interventions in Aging 9: 1175-1186.

15. McCook JP (2016) Topical Products for the Aging Face. Clinics in Plastic Surgery 43(3): 597-604.

16. Zouboulis CC, Ganceviciene R, Liakou AI, Theodoridis A, Elewa R, et al. (2019) Aesthetic aspects of skin aging, prevention, and local treatment. Clin Dermatol 37(4): 365-372.

17. Al-Niaimi, Zhen Chiang NY (2017) Topical Vitamin C and the skin: Mechanisms of action and Clinical applications. Journal of Clinical and Aesthetic Dermatology 10(7): 1417.

18. Zanna N (2015) Maximising treatment outcomes with skin peels: products, preparation and procedures. J Aesthetic Nurs 4(4): 172-180.

19. McDaniel D, Farris P, Valacchi G (2018) Atmospheric skin aging-Contributors and inhibitors. Journal of Cosmetic Dermatology 17(2): 124-137.

20. Mukherjee S, Date A, Patravale V, Korting HC, Roeder A, et al. (2006) Retinoids in the treatment of skin aging: an overview of clinical efficacy and safety. Clin Interv Aging 1(4): 327-348.

21. Tran D, Townley JP, Barnes TM, Greive KA (2014) An antiaging skin care system containing alpha hydroxy acids and vitamins improves the biomechanical parameters of facial skin. Clin Cosmet Investig Dermatol 8: 9-17.
22. Martín Ortega M, Segura Campos MR (2019) Bioactive Compounds as Therapeutic Alternatives. Bioactive Compounds pp: 247-264.

23. The efficacy and tolerability of hydroxy acids in males with moderate to severe photoaging. J Am Acad Dermatol.

24. Thomas JR, Dixon TK, Bhattacharyya TK (2013) Effects of Topicals on the Aging Skin Process. Facial Plastic Surgery Clinics of North America 21(1): 55-60.

25. Stellavato A, Adriana Pirozzi AV, Donato S, Scognamiglio I, Reale S, et al. (2018) Positive Effects against UV-A Induced Damage and Oxidative Stress on an in Vitro Cell Model Using a Hyaluronic Acid Based Formulation Containing Amino Acids, Vitamins, and Minerals. Biomed Res Int: 8481243.

26. Russo L, Spagnuolo C, Russo M, Tedesco I, Moccia S, et al. (2019) Mechanisms of aging and potential role of selected polyphenols in extending healthspan. Biochemical Pharmacology 173: 113719.

27. Mohammad S, Naveed M, Ijaz S, Shumzaid M, Hassan S, et al. (2018) Phytocosmeceutical formulation development, characterization and its in-vivo investigations. Biomed Pharmacother 107: 806-817.

28. Kim H, Lee JE, Kim KM, Kang NJ (2018) Beneficial effects of marine algae-derived carbohydrates for skin health. Marine Drugs 16(11): 459.

29. Berthon Y, Nachat-Kappes R, Bey M, Cadoret JP, Renimel I, et al. (2017) Marine algae as attractive source to skin care. Free Radical Research 51(6): 555-567.

30. Agrawal S, Adholeya A, Barrow CJ, Deshmukh SK (2018) Marine fungi: An untapped bioresource for future cosmeceuticals. Phytochemistry Letters 23: 15-20.

31. Hardeland R (2013) Melatonin and the theories of aging: A critical appraisal of melatonin's role in antiaging mechanisms. Journal of Pineal Research 55(4): 325-56.

32. Yokoyama Y, Akita H, Hasegawa S, Negishi K, Akamatsu $\mathrm{H}$, et al. (2014) Histologic study of collagen and stem cells after radiofrequency treatment for aging skin. Dermatologic Surg 40(4): 390-397.

33. Atiyeh S, Ibrahim AE, Saad DA (2013) Stem cell facelift: Between reality and fiction. Aesthetic Surg J 33(3) 334338.

34. Ramaut, Hoeksema H, Pirayesh A, Stillaert F, Monstrey S (2018) Microneedling: Where do we stand now? A systematic review of the literature. J Plast Reconstr Aesthetic Surg 71(1): 1-14. 


\section{Clinical Dermatology Open Access Journal}

35. Lasers and Energy Devices for the Skin. Informa Healthcare, 2013.

36. Lee JC, Daniels MA, Roth MZ (2016) Mesotherapy, Microneedling, and Chemical Peels. Clinics in Plastic Surgery 43(3): 583-595.

37. Connor O, Lowe PM, Shumack S, Lim AC, Prince R (2017) Chemical peels : A review of current practice. Australas J Dermatol 59(3): 171-181.

38. Soleymani T, Lanoue J, Rahman Z (2018) A Practical Approach to Chemical Peels: A Review of Fundamentals and Step-by-step Algorithmic Protocol for Treatment. J Clin Aesthet Dermatol 11(8): 21-28.

39. Wójcik, Kubiak M, Rotsztejn H (2013) Influence of azelaic and mandelic acid peels on sebum secretion in ageing women. Postepy Dermatol Alergol 30(3): 140-145.

40. Kattimani V, Tiwari RVC, Gufran K, Wasan B, Shilpa PH, et al. (2019) Botulinum toxin application in facial esthetics and recent treatment indications (2013-2018). Journal of International Society of Preventive and Community Dentistry 9(2): 99-105.

41. Abduljabbar H, Basendwh MA (2016) Complications of hyaluronic acid fillers and their managements. J Dermatology Dermatologic Surg 20(2): 100-106.
42. Jandhyala R (2015) Dermal Fillers for Facial Rejuvenation: A Review of Clinical Evidence. J Aesthetic Med 1(1): 6-13.

43. Rivkin Z (2016) Volume correction in the aging hand: Role of dermal fillers. Clinical Cosmetic and Investigational Dermatology 9: 225-232.

44. Goo B, Rho NK, Yoo K (2016) A comparison study of different wavelengths and cosmeceuticals in the combination treatment of fractional laser and antiaging cosmeceuticals. Lasers Surg Med 48(4): 434.

45. Beri K (2016) Breathing to younger skin: 'reversing the molecular mechanism of skin aging with yoga. Futur Sci OA 2(2): FSO122.

46. Gkogkolou P, Böhm M (2012) Advanced glycation end products: Keyplayers in skin aging? DermatoEndocrinology 4(3) 259-270.

47. Zhang S, Duan E (2018) Fighting against Skin Aging : The Way from Bench to Bedside. Cell Transplant 27(5): 729738.

48. Costa R, Santos L (2017) Delivery systems for cosmeticsFrom manufacturing to the skin of natural antioxidants. Powder Technology 322: 402-416. 